\title{
REGIMES DO VENTO À SUPERFÍCIE NA ÁREA DE PETROLINA, SUBMÉdIO SÃO FRANCISCO
}

\author{
EWERTON CLEUDSON DE SOUSA MELO ${ }^{1}$, MARIA REGINA DA SILVA ARAGÃO², MAGALY \\ DE FATIMA CORREIA ${ }^{2}$
}

\author{
${ }^{1}$ Faculdade Maurício de Nassau, Campina Grande, PB, Brasil \\ ${ }^{2}$ Universidade Federal de Campina Grande, Campina Grande, PB, Brasil \\ ecsmelo@yahoo.com,regina@dca.ufcg.edu.br, magaly@dca.ufcg.edu.br
}

Recebido Fevereiro de 2012 - Aceito Julho de 2013

\begin{abstract}
RESUMO
Neste trabalho o ciclo diário do vento à superfície é investigado com ênfase na variação sazonal e nas circulações locais. Os dados da estação automática instalada a 25-30 km de Petrolina, e da estação convencional localizada na cidade são utilizados. Os resultados mostram que as velocidades médias horárias aumentam (diminuem) no decorrer do trimestre abril-maio-junho (outubro-novembrodezembro), devido à intensificação (enfraquecimento) da alta subtropical do Atlântico Sul. No trimestre julho-agosto-setembro os valores são máximos e muito próximos, com direção no intervalo 120-130 graus. $\mathrm{O}$ ciclo diário tem um máximo de intensidade às 8-9 HL (hora local) e dois mínimos, um às 5-6 HL e outro às 17-18 HL, em todos os meses. Os hodógrafos do vento local nas duas estações mostram circulações fracas de janeiro a maio, uma característica que pode estar relacionada com o maior teor de umidade do solo e, consequentemente, com valores mais baixos do gradiente do fluxo de calor sensível. No restante do ano, período de estiagem, as circulações locais são comparativamente fortes. Os hodógrafos apresentam forma irregular que indica um regime preferencial na direção sudeste-noroeste. As circulações locais são mais intensas às 9 e $18 \mathrm{HL}$, horários de máxima e mínima velocidade no ciclo diário, respectivamente.
\end{abstract}

Palavras-chave: ciclo diário do vento, circulação local, ventos alísios, sazonalidade, Nordeste do Brasil

\begin{abstract}
SURFACE WIND REGIMES IN THE PETROLINA AREA, LOWER-MIDDLE SÃO FRANCISCO

In this work the daily surface wind cycle is investigated focusing on the seasonal variation and the local circulations. The data collected by the automatic station located $25-30 \mathrm{~km}$ far from Petrolina and by the conventional station located in the city are used. The results show that the hourly mean wind speeds increase (decrease) during April-May-June (October-November-December) due to the intensification (weakening) of the South Atlantic subtropical high. During the three-month period July-August-September the hourly wind speeds are very close and have their highest intensities, with wind direction in the interval 120-130 degrees. In general, the daily cycle gives evidence of a maximum at 8-9 LT (local time) and two minima, one at 5-6 LT and another at 17-18 LT, in every month. The hodographs of the local wind at both stations show weak local circulations from January to May, a characteristic that may be related to a higher soil moisture content and, as a consequence, to lower values of the sensible heat flux gradient. During the remaining of the year, the dry period, the local circulations are comparatively stronger. The hodographs are irregularly drawn suggesting one local wind regime, in the southeast-northwest direction. The local circulations are stronger at 9 and $18 \mathrm{LT}$, the times of maximum and minimum wind speeds during the daily cycle, respectively. Keywords: daily wind cycle, local circulation, trade winds, seasonality, Northeast Brazil
\end{abstract}




\section{INTRODUÇÃO}

Compreender a variabilidade espacial e temporal do vento à superfície tem grande importância, porque ele é responsável pelo transporte de umidade e calor necessário à formação de nuvens e de sistemas convectivos. $\mathrm{O}$ vento à superfície influencia direta ou indiretamente diversas atividades humanas, a exemplo das operações de pouso e decolagem de aeronaves, a pesca marítima (embarcações veleiras), a irrigação, particularmente quando feita por aspersão ou gotejamento, entre outras (McKendry, 1983). O vento é uma das variáveis fundamentais na determinação da climatologia de uma região e, conforme Alpert e Mendel (1986), é a variável atmosférica mais sensível às mudanças climáticas.

$\mathrm{O}$ vento pode ser originado por contrastes térmicos em grande escala ou escala local. Os efeitos locais considerados clássicos são as brisas de vale-montanha e marítima-terrestre, e os não convencionais são os ventos (brisas) gerados por contrastes térmicos entre áreas de diferentes características da superfície, tais como, descontinuidade na cobertura vegetal e no tipo de solo (Mahfouf et al., 1987). Os sistemas de brisa são mais intensos no horário de maior instabilidade atmosférica pelo aquecimento diurno e, dessa forma, determinam horários preferenciais para a ocorrência de precipitação pluvial. Nas situações em que as brisas interagem de forma favorável com sistemas de escala maior, as nuvens são mais profundas e as chuvas mais abundantes (Melo, 2000; Barbosa e Correia, 2005).

A variabilidade do escoamento em determinado local depende da região e da época do ano, sendo influenciada pela fisiografia e pela ocorrência de fenômenos sazonais ou anomalias atmosféricas de grande escala. No estudo desta variabilidade normalmente utilizam-se modelos numéricos regionais, cujos resultados precisam ser validados com base em dados coletados com resolução adequada.

As Plataformas de Coleta de Dados Automáticas PCD's possibilitam armazenar, com alta resolução temporal, determinado número de variáveis meteorológicas. Assim, contribuem de forma decisiva para solucionar alguns problemas de validação. Inicialmente esse sistema era significativamente oneroso, motivo pelo qual foi instalado em um número restrito de municípios selecionados, a exemplo de Petrolina, em Pernambuco.

A cidade de Petrolina, localizada no sudoeste do estado de Pernambuco, é uma das principais cidades da região do submédio São Francisco. Ela se destaca pela atividade agrícola com o cultivo irrigado de frutas, em especial videiras, que tem elevada importância econômica e social, na medida em que envolve grande volume anual de negócios voltados para os mercados interno e externo, sendo a que apresenta o maior coeficiente de geração de empregos diretos e indiretos na região (EMBRAPA SEMI-ÁRIDO, 2004).
O potencial de desenvolvimento da bacia do Rio São Francisco e, em particular, de Petrolina, torna relevante investigar a existência de circulações que influenciam o transporte de umidade e a precipitação na região. Dessa forma, a compreensão sobre as circulações locais e sua interação com a grande escala poderá auxiliar no planejamento e gerenciamento agrícola e no aperfeiçoamento de modelos numéricos regionais para simulação de alterações climáticas e previsão do tempo e clima local. Nesse contexto, o objetivo deste trabalho é examinar os regimes do vento à superfície na região de Petrolina com foco na variação sazonal e horária dessa variável climática.

\section{2. ÁREA DE ESTUDO}

Petrolina $\left(9^{\circ} 24^{\prime} \mathrm{S}, 40^{\circ} 29^{\prime} \mathrm{W}, 370 \mathrm{~m}\right)$ está localizada na margem esquerda do Rio São Francisco, a cerca de $40 \mathrm{~km}$ da represa de Sobradinho. Na Figura 1, que ilustra a topografia numa área quadrangular de $1^{\circ} \times 1^{\circ}$ que abrange parte dos estados de Pernambuco e Bahia, a localização da cidade é indicada pelo círculo acima da sigla INMET. O relevo do município de Petrolina é suavemente ondulado, com altitudes entre 800 e 200 m (COMPANHIA DE DESENVOLVIMENTO DOS VALES DO SÃO FRANCISCO E DO PARNAÍBA, 2004). Petrolina dista da base das colinas situadas ao norte, sul e oeste - que têm altitudes máximas de 500, 700 e $500 \mathrm{~m}$ - de aproximadamente $12,5 \mathrm{~km}, 13,96 \mathrm{~km}$ e $30,2 \mathrm{~km}$, respectivamente. A vegetação nativa predominante é do tipo caatinga hiperxerófila (Correia, 2001; Correia et al., 2006a).

A estação chuvosa em Petrolina começa em novembro/ dezembro e termina em março/abril (Ramos, 1975; Silva Aragão et al., 1997). O início das chuvas está associado à atuação do cavado de ar superior do Atlântico Sul/vórtices ciclônicos de ar superior (Kousky e Gan, 1981) e de sistemas frontais austrais que penetram na Região Nordeste (Kousky, 1979), e o final, à posição mais ao sul da Zona de Convergência Intertropical (ZCIT). Ramos (1975) destaca que a frequência de ocorrência de precipitação é máxima no período da manhã (tarde) em Petrolina (nas áreas elevadas a oeste da cidade). Ele credita essa distribuição à interação entre o escoamento de grande escala (ventos alísios) e o escoamento local gerado pela desigualdade no aquecimento/esfriamento entre a área das encostas e do vale. A importância da topografia no desenvolvimento de circulações locais na região de Petrolina é evidenciada em experimentos numéricos de alta resolução realizados com o modelo Regional Atmospheric Modeling System (RAMS) (Correia et al., 2006b). Os experimentos mostram ainda que a estrutura termodinâmica da atmosfera é outro fator que influencia a intensidade dos ventos locais.

As condições atmosféricas em Petrolina são caracterizadas pela presença de ventos do quadrante sudeste e 


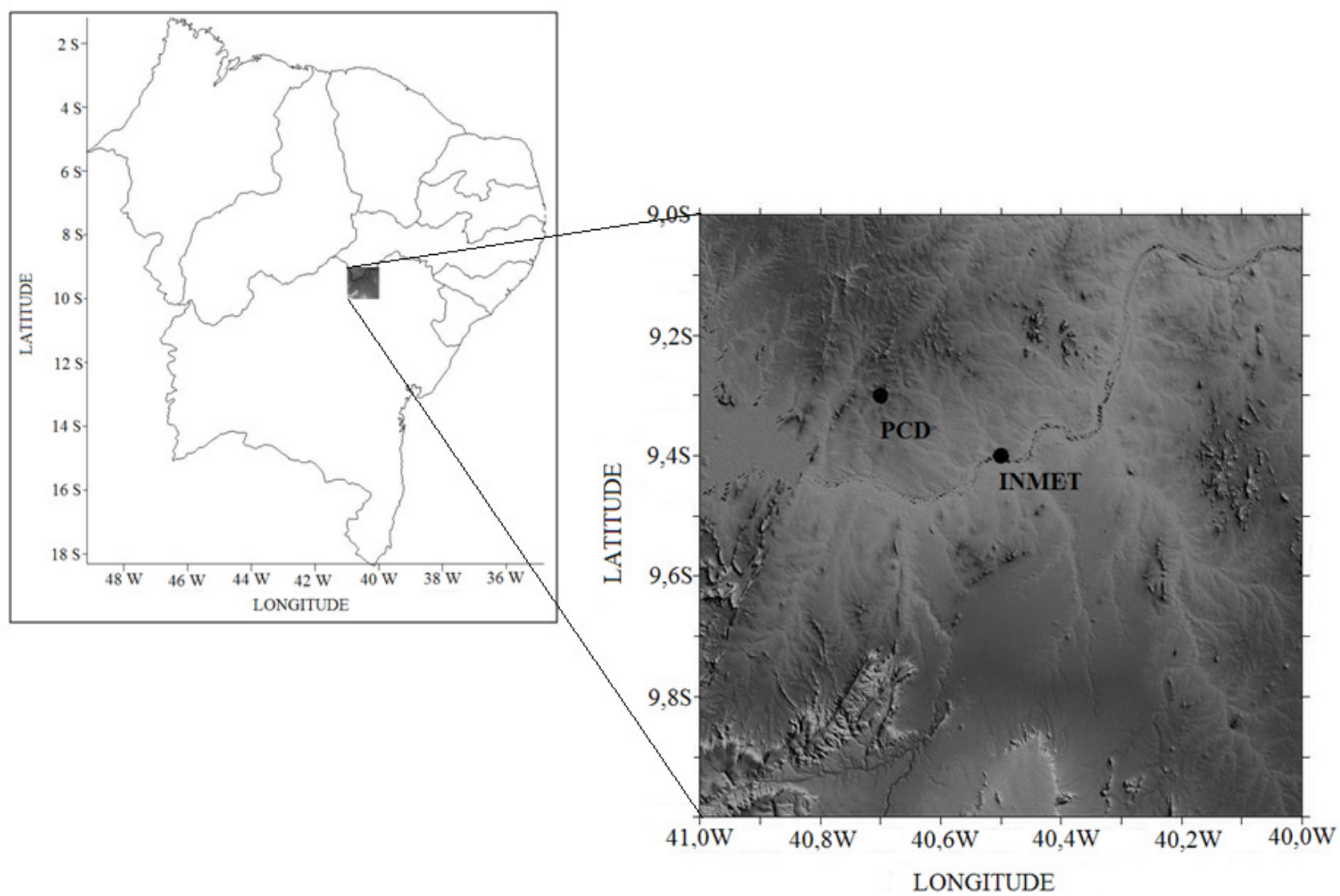

Figura 1 - Mapa da divisão política do Nordeste do Brasil com destaque para a representação tridimensional do relevo na área delimitada no mapa. A posição geográfica da plataforma automática de coleta de dados (PCD) e da estação convencional de superfície (INMET) é indicada no destaque. A estação do INMET está situada no perímetro urbano da cidade de Petrolina, Pernambuco.

Fonte dos dados topográficos: Projeto TOPEX, disponibilizado pelo Laboratório de Recursos Hídricos e Sensoriamento Remoto da Paraíba (LMRS).

de uma inversão de subsidência na baixa troposfera devido ao domínio da Alta Subtropical do Atlântico Sul (ASAS), que é mais intensa no final do outono e no inverno austral (Ramos, 1975). Essa inversão parece inibir a formação de chuvas isoladas mantendo baixa a quantidade de precipitação. Entretanto, os cúmulos de convecção profunda podem se desenvolver sobre áreas específicas da superfície e também na presença de outros sistemas atmosféricos organizados (Zona de Convergência Intertropical, cavado de ar superior do Atlântico Sul/vórtices ciclônicos de ar superior, sistemas frontais austrais), que causam enfraquecimento ou interrupção no regime dos ventos alísios de sudeste e o enfraquecimento ou eliminação da inversão, favorecendo o desenvolvimento e a organização da convecção profunda e, consequentemente, a formação de sistemas convectivos de mesoescala (Silva Aragão et al., 2000; Souza, 2003; Diniz et al., 2004; Barbosa e Correia, 2005; Silva Aragão et al., 2007; Santos Silva et al., 2008).

Vários estudos mostram que grandes eventos de chuva ocorridos na área de Petrolina estiveram associados a sistemas convectivos de mesoescala formados na presença: (a) do cavado de ar superior do Atlântico Sul em janeiro, (b) de um vórtice ciclônico de ar superior em março, (c) da Zona de Convergência Intertropical em abril; (d) de um sistema de origem frontal em junho (Damião, 1999; Souza, 2003; Barbosa e Correia, 2005; Moscati e Gan, 2006; Silva Aragão et al., 2007; Santos Silva et al., 2008). Em particular, o estudo de Silva Aragão et al. (2007) para janeiro de 1985 documenta a interrupção das chuvas em Petrolina nos dias em que o vento à superfície é forte e do quadrante sudeste, uma condição que indica o domínio da ASAS na região.

\section{DADOS E METODOLOGIA}

\subsection{Dados}

Tendo como objetivo investigar os regimes do vento à superfície na área de Petrolina, os dados disponíveis de duas estações meteorológicas localizadas no município foram utilizados: da plataforma de coleta de dados (PCD) automática à superfície ( $\left.9^{\circ} 9^{\prime} \mathrm{S}, 40^{\circ} 22^{\prime} \mathrm{W}, 366 \mathrm{~m}\right)$, instalada numa encosta situada a uma distância entre 25 e 30 km do Rio São Francisco, e da estação convencional de superfície do INMET $\left(9^{\circ} 23^{\prime} \mathrm{S}\right.$, 
$40^{\circ} 30^{`} \mathrm{~W}, 376 \mathrm{~m}$ ), instalada próximo da margem do rio (Figura 1). As medidas do vento dessa última estação foram obtidas por um anemógrafo universal Fuess instalado a $10 \mathrm{~m}$ de altura. Esses dados foram processados pela Unidade Acadêmica de Ciências Atmosféricas da Universidade Federal de Campina Grande, obtendo-se valores para as horas inteiras, ou seja, 24 pares de valores diários, do período de 1977 a 1981 . A direção do vento foi determinada considerando as oito direções principais da rosa dos ventos, além dos casos de calmaria. Esses dados foram utilizados em estudos anteriores (Correia, 2000; Barreto, 2001; Silva et al., 2004, entre outros) e estão disponíveis na Unidade Acadêmica de Ciências Atmosféricas. Nas análises foram considerados todos os meses do período de 1977 a 1981.

As medidas da direção e velocidade do vento da PCD operada pelo Laboratório de Meteorologia do Instituto Tecnológico de Pernambuco (LAHMEPE/ITEP) foram obtidas por um anemômetro sônico tridimensional instalado a $10 \mathrm{~m}$ de altura. Detalhes técnicos sobre a PCD e o anemômetro sônico podem ser encontrados em Handar Models 425A/425AH Ultrasonic Wind Sensors Guide (1999) ou no endereço eletrônico http://satelite.cptec.inpe.br/PCD/. Os dados foram disponibilizados em intervalos de três horas, ou seja, 8 pares de valores diários correspondentes às horas inteiras múltiplas de três, para o período de 2001 a 2007, com exceção do ano de 2003. Nas análises foram considerados apenas os meses em que o número de valores disponíveis era superior a $95 \%$ do número máximo de dados para o mês em questão. O Tabela 1 mostra que o maior número de falhas (3) ocorre no primeiro quadrimestre do ano.

O fato da resolução temporal dos dados da PCD não ser a mais adequada para estudos da variabilidade do vento na escala de tempo diária, torna necessário fazer algumas considerações. Dados com essa resolução temporal podem mascarar parte das variações que caracterizam o ciclo diário. Essa hipótese foi testada utilizando os dados da estação do INMET com a ressalva de que os resultados servem apenas como um indicativo do que pode ocorrer no caso da PCD. Um exemplo é visto na Figura 2 através dos gráficos da variação horária da velocidade do vento utilizando os dados médios mensais do período, com resolução de 1 hora (Figura 2a) e de 3 horas (Figura 2b), para os três primeiros meses do ano. É possível observar dois máximos e dois mínimos nos dois gráficos. Por outro lado, a magnitude e o horário do mínimo e máximo que ocorrem no início da manhã diferem entre os gráficos. O máximo principal é visto às $8 \mathrm{HL}$ no gráfico (a) e às $9 \mathrm{HL}$ no gráfico (b), com valores menores no gráfico (b): $3 \mathrm{~m} / \mathrm{s} \rightarrow 2,8 \mathrm{~m} / \mathrm{s}$ em janeiro, $3,8 \mathrm{~m} / \mathrm{s} \rightarrow 3,6 \mathrm{~m} / \mathrm{s} \mathrm{em}$ fevereiro, e $3,3 \mathrm{~m} / \mathrm{s} \rightarrow 3,0 \mathrm{~m} / \mathrm{s}$ em março, diferenças essas que ficam em torno de $10 \%$. O mínimo secundário é visto às $5 \mathrm{HL}$ no gráfico (a); no gráfico (b) ele ocorre às $3 \mathrm{HL}$ em janeiro e março, e às $5 \mathrm{HL}$ em fevereiro. As magnitudes da intensidade mínima são maiores no gráfico (b); os valores também diferem em torno de $10 \%$ nos três meses.

No exemplo acima é evidente que a resolução temporal de três horas não alterou as características gerais do ciclo diário, mas prejudicou a determinação do horário e intensidade de valores extremos, o que aponta para a importância da disponibilidade de dados do vento com resolução horária.

\subsection{Metodologia}

A metodologia descrita a seguir foi aplicada aos dois conjuntos de dados com o objetivo de caracterizar o escoamento em dois locais do município de Petrolina, com enfoque nos seguintes aspectos: (a) a variação sazonal do ciclo diário do vento e (b) a existência e variação sazonal de circulações locais.

Tabela 1 - Dados do vento à superfície coletados em Petrolina pelo LAHMEPE/ITEP. (x) indica mês utilizado, (-) indica mês não utilizado

\begin{tabular}{|c|c|c|c|c|c|c|c|c|c|c|c|c|}
\hline \multirow{2}{*}{ ANO } & \multicolumn{9}{|c|}{ MÊS } & \multicolumn{1}{|c|}{} \\
\cline { 2 - 14 } & Jan & Fev & Mar & Abr & Mai & Jun & Jul & Ago & Set & Out & Nov & Dez \\
\hline 2001 & - & - & - & - & $\mathbf{x}$ & $\mathbf{x}$ & $\mathbf{x}$ & $\mathbf{x}$ & $\mathbf{x}$ & $\mathbf{x}$ & $\mathbf{x}$ & $\mathbf{x}$ \\
\hline 2002 & $\mathbf{x}$ & $\mathbf{x}$ & $\mathbf{x}$ & $\mathbf{x}$ & $\mathbf{x}$ & $\mathbf{x}$ & $\mathbf{x}$ & $\mathbf{x}$ & $\mathbf{x}$ & - & - & - \\
\hline 2003 & - & - & - & - & - & - & - & - & - & - & - & - \\
\hline 2004 & - & - & - & - & - & - & $\mathbf{x}$ & $\mathbf{x}$ & $\mathbf{x}$ & $\mathbf{x}$ & $\mathbf{x}$ & $\mathbf{x}$ \\
\hline 2005 & $\mathbf{x}$ & $\mathbf{x}$ & $\mathbf{x}$ & $\mathbf{x}$ & $\mathbf{x}$ & $\mathbf{x}$ & $\mathbf{x}$ & $\mathbf{x}$ & $\mathbf{x}$ & $\mathbf{x}$ & $\mathbf{x}$ & $\mathbf{x}$ \\
\hline 2006 & $\mathbf{x}$ & $\mathbf{x}$ & $\mathbf{x}$ & $\mathbf{x}$ & $\mathbf{x}$ & $\mathbf{x}$ & $\mathbf{x}$ & $\mathbf{x}$ & $\mathbf{x}$ & $\mathbf{x}$ & $\mathbf{x}$ & $\mathbf{x}$ \\
\hline 2007 & $\mathbf{x}$ & $\mathbf{x}$ & $\mathbf{x}$ & $\mathbf{x}$ & $\mathbf{x}$ & $\mathbf{x}$ & $\mathbf{x}$ & $\mathbf{x}$ & $\mathbf{x}$ & $\mathbf{x}$ & $\mathbf{x}$ & $\mathbf{x}$ \\
\hline
\end{tabular}




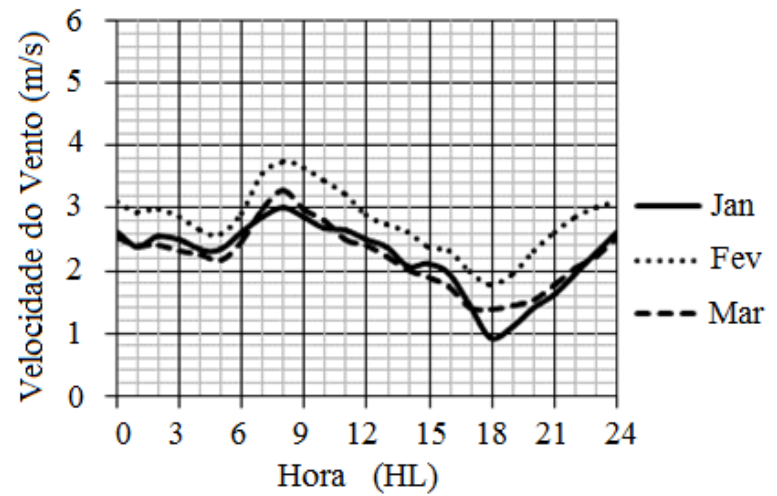

(a)

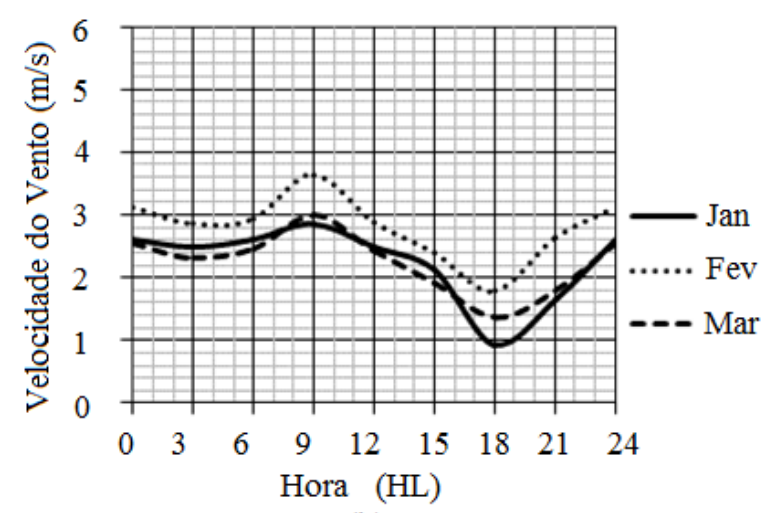

(b)

Figura 2 - Ciclo diário da velocidade do vento à superfície observada no primeiro trimestre do período 1977-1981 na estação do INMET em PetrolinaPE, com base em dados com resolução temporal de: (a) uma hora e (b) três horas. Observe que os valores às 0 e 24 HL (hora local) são iguais. Fonte: DCA/UFCG e INMET.

Os dados horários do vento à superfície $(\vec{V})$ foram decompostos nas componentes zonal $(u)$ e meridional $(v)$ de acordo com

$$
u=-|\vec{V}| \operatorname{sen} \theta \text { e } v=-|\vec{V}| \cos \theta,
$$

em que $|\vec{V}|$ é a intensidade ou velocidade do vetor vento $\vec{V}$, e $\theta$ é a sua direção.

Feita a decomposição do vento à superfície, as componentes horárias médias mensais para cada ano foram determinadas usando a expressão

$$
V_{h m a}=\frac{\sum_{d=1}^{D} V_{h d m a}}{N_{d}},
$$

em que $V$ representa a componente do vento (zonal ou meridional) e os sub-índices indicam: $h$, a hora; $d$, o dia; $m$, o mês; $a$, o ano. O símbolo $D$ representa o último dia e $N_{d}$ representa o número de dias com observação do vento na hora $h$, do mês $m$, do ano $a$.

As médias horárias mensais para o conjunto dos anos foram determinadas por

$$
V_{h m}=\frac{\sum_{a=1}^{A} V_{h m a}}{N_{a}},
$$

em que $A$ é o último ano e $N_{a}$ é o número de anos. A seguir, esses valores foram utilizados para calcular a velocidade e a direção do vento horário médio ilustrado nas Figuras 3 e 5.

O vento $(\vec{V})$ é uma grandeza vetorial que pode ser expressa como a soma de um vetor velocidade média $\vec{V}$ e um vetor velocidade de flutuação $\vec{V}^{\prime}$. No presente caso, a média $\overrightarrow{\vec{V}}$ representa o vento médio diário ou vento sinótico e a flutuação $\vec{V}^{\prime}$ o vento local existente no horário da observação. Dessa forma, $\vec{V}^{\prime}=\vec{V}-\overrightarrow{\vec{V}}$. Logo, $\vec{V}$ é o vetor vento observado.

A determinação das componentes médias mensais do vento local exigiu a obtenção prévia das componentes do vento sinótico diário $\overline{\vec{V}}$ para cada mês e ano através da expressão

$$
\bar{V}_{d m a}=\frac{\sum_{h=1}^{H} V_{h d m a}}{N_{h}},
$$

em que o símbolo $H$ representa a última hora e $N_{h}$ é o número de horas com observação no dia $d$, do mês $m$, do ano $a$. As componentes do vento local $\vec{V}^{\prime}$ para cada hora, dia, mês e ano foi obtida usando a expressão

$$
V_{h d m a}^{\prime}=V_{h d m a}-\bar{V}_{d m a} .
$$

As componentes horárias médias do vento local para cada mês e ano foram determinadas por

$$
V_{h m a}^{\prime}=\frac{\sum_{d=1}^{D} V_{h d m a}^{\prime}}{N_{d}} .
$$

Assim, as médias horárias mensais do vento local para o conjunto dos anos foram determinadas por

$$
V_{h m}^{\prime}=\frac{\sum_{a=1}^{A} V_{h m a}^{\prime}}{N_{a}} .
$$

Os valores obtidos são ilustrados nos hodógrafos vistos nas Figuras 4 e 6.

\section{RESULTADOS E DISCUSSÃO}

$\mathrm{Na}$ discussão a seguir as duas séries de dados são tratadas separadamente já que os períodos são diferentes, o que inviabiliza comparações diretas entre os resultados. Outro aspecto considerado na discussão é o fato de que as duas estações estão localizadas à esquerda do Rio São Francisco, mas em áreas de aspecto geográfico distinto conforme assinalado na Seção 2. Essa diferença é fundamental, tendo em vista que o ciclo diário do vento e, consequentemente, as circulações locais, são um dos focos deste trabalho. O relevo é um fator determinante na geração dessas circulações na região. Outros fatores como 
o teor de umidade e a cobertura vegetal do solo também são importantes, conforme mostrado por Correia et al. (2006b). Esses três fatores influenciam de forma diferenciada as duas estações; no caso da estação convencional há um fator adicional que é a proximidade do rio, o que contempla a possibilidade de que brisas fluviais alterem o teor de umidade local através do transporte dessa propriedade atmosférica.

\subsection{Análise dos dados da estação automática}

A variação sazonal do ciclo diário do vento na PCD é ilustrada pela velocidade (Figuras 3a-3d) e direção (Figuras $3 e-3 h)$. É evidente na Figuras $3 a-3 d$ que as velocidades menores (maiores) estão no primeiro (terceiro) trimestre. $\mathrm{O}$ aumento da velocidade entre fevereiro (Figura 3a) e agosto (Figura 3c) está relacionado com a intensificação da ASAS e das circulações locais como será visto mais adiante. É possível observar ainda maior variação no segundo trimestre, marcando a transição entre o período chuvoso e o período de estiagem (Figura $3 b)$. O oposto ocorre no terceiro trimestre, que tem valores mensais muito próximos (Figura 3c). Os gráficos da Figuras 3e-3h mostram direções do quadrante sudeste, com exceção de fevereiro, quando o quadrante nordeste também é visto (Figura 3e). A variação da direção entre os meses é pequena, exceto no primeiro trimestre (Figura 3e). Nesse período, época chuvosa na região, o aumento da nebulosidade e a ocorrência de chuva afetam o balanço de energia à superfície. Esses fatores aumentam a variabilidade nos fluxos turbulentos em superfície (calor sensível e calor latente), que está diretamente associada com variações na temperatura e circulações locais.

O ciclo diário mostra um padrão complexo nos gráficos da velocidade (Figuras 3a-3d): há um máximo no meio da manhã (9 HL) e dois mínimos, um no início da manhã (6 HL), e outro no final da tarde (18 HL) ou início da noite $(21 \mathrm{HL})$. Um máximo secundário é visto à noite, mas tem horário variável e é evidente somente em alguns meses, o que pode ser ocasionado, em parte, pela resolução temporal dos dados. Enquanto isso, o ciclo diário da direção (Figuras 3e-3h) mostra pouca variação, principalmente no segundo e terceiro trimestres (Figuras 3f-3g), quando a direção permanece em torno de 120 graus. No primeiro e quarto trimestres as variações são relativamente maiores, principalmente entre o período diurno e o período noturno (Figuras 3e-3h). A pequena variação da direção resulta do domínio da circulação de grande escala (ASAS) enquanto que o padrão complexo visto no ciclo diário da velocidade (Figuras 3a-3d) é indicativo da interação entre essa circulação (ventos alísios) e circulações locais.

As circulações locais são investigadas através de hodógrafos elaborados com base nos valores médios mensais do vento local diário. Nos hodógrafos os eixos dos gráficos foram orientados com o norte na direção do topo da página. Os números de 0 a 21 representam as horas locais, e a posição em que aparecem no gráfico, em analogia com o movimento dos ponteiros de um relógio, determina o sentido de rotação do vento local ao longo do dia, ou seja, horário ou anti-horário. Normalmente, no hemisfério norte a rotação do vento é no sentido horário, devido à força de Coriolis. Porém, em alguns locais o sentido da rotação é fortemente influenciado por gradientes de pressão associados com fatores locais como a topografia (Kusuda e Alpert, 1983). Idealmente, os hodógrafos têm forma elíptica (Haurwitz, 1947), mas geralmente não seguem a forma teórica devido à influência de fatores fisiográficos (Dexter, 1957).

A variação sazonal das circulações locais é ilustrada pela Figura 4 evidenciando que elas são mais intensas no terceiro e quarto trimestres (Figuras 4g-341), e no final do segundo trimestre (Figura 4f), época de estiagem na região. A baixa intensidade na época chuvosa (Figuras 4a-4e) tem como causa principal o maior teor de umidade do solo. A presença de umidade no solo faz com que parte da energia disponível para o aquecimento da superfície seja utilizada para evaporação (fluxo de calor latente). Consequentemente, a diferença nos gradientes de temperatura gerados por descontinuidades na cobertura do solo é reduzida, o que ocasiona uma circulação local menos intensa devido a valores mais baixos do gradiente do fluxo de calor sensível. Esse resultado foi encontrado por Correia et al. (2006b) para a região de Petrolina, através da análise da intensidade da circulação da brisa lacustre gerada pelo contraste terra-água, que é determinado pela intensidade do gradiente de temperatura (bem definido pela diferença entre a temperatura da água e do solo).

A direção principal da circulação local é determinada com base no eixo maior dos hodógrafos mensais. Na latitude de Petrolina, o efeito de Coriolis é desprezível em comparação com o efeito do gradiente de pressão (forçante térmica). A configuração dos hodógrafos indica a existência de um regime preferencial que pode estar associado à declinação solar, já que ela determina o ângulo com que os raios solares incidem na superfície e, consequentemente, a taxa de aquecimento da mesma. De maneira geral, esse regime tem o eixo maior na direção sudeste-noroeste (Figura 4), de forma que o vento local é do quadrante sudeste no período diurno e do quadrante noroeste no período noturno. Esse padrão implica num escoamento em direção à serra (área mais aquecida) no período diurno e o oposto no período noturno, indicando o domínio de ventos anabáticos durante o dia e catabáticos à noite. $\mathrm{O}$ giro do vento local ao longo do dia é predominantemente anti-horário, exceto nos meses de abril (Figura 4d) e maio (Figura 4e). Mudanças no sentido de rotação são observadas em curtos períodos de tempo, à noite e de madrugada. Uma explicação para essa variabilidade pode 


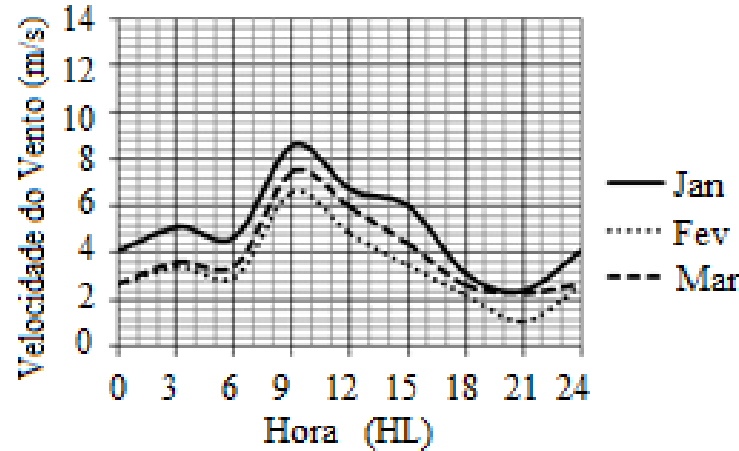

(a)

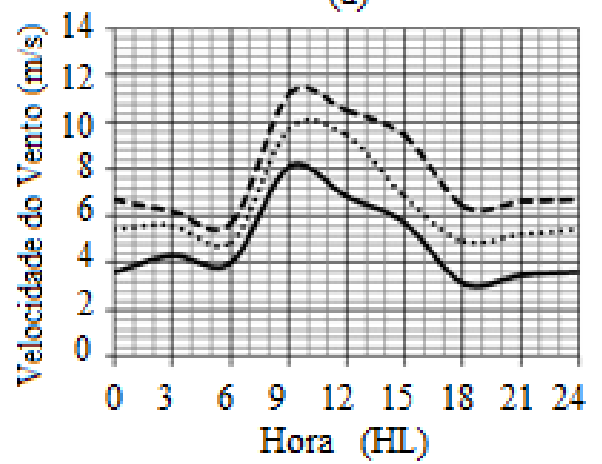

(b)

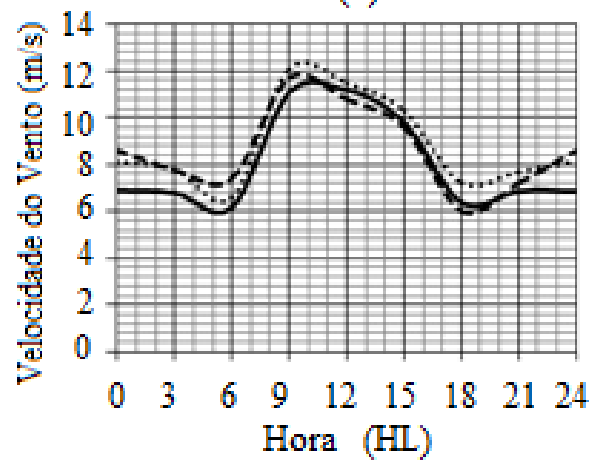

(c)

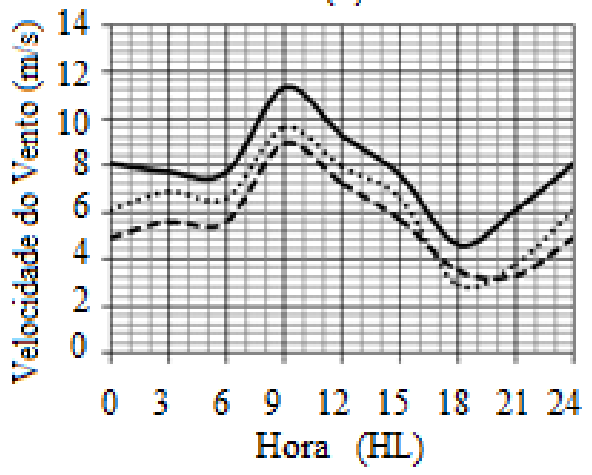

(d)

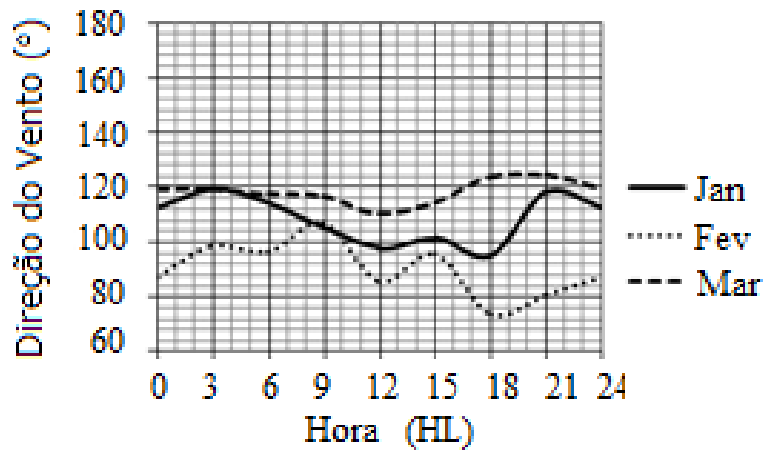

(e)

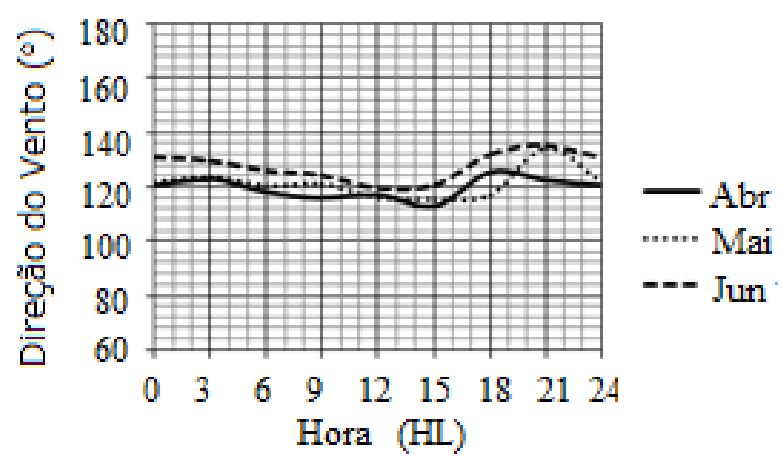

(f)

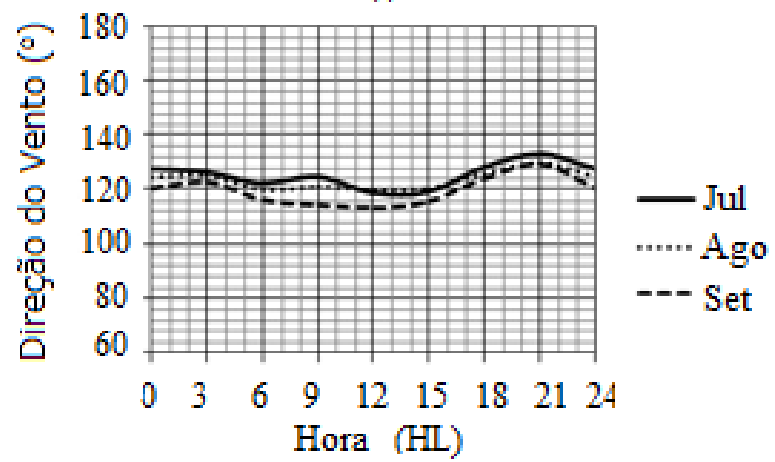

(g)

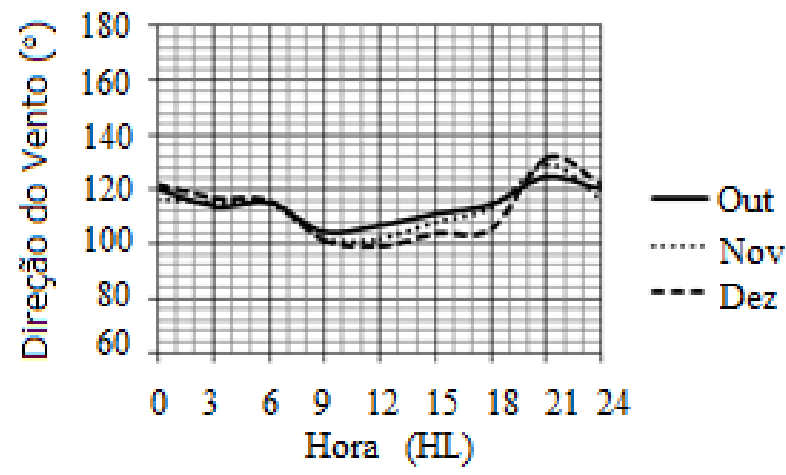

(h)

Figura 3 - Variação sazonal do ciclo diário da velocidade (a,b,c,d) e da direção (e,f,g,h) do vento à superfície na Plataforma de Coleta de Dados (PCD) de Petrolina-PE para os trimestres: (a,e) janeiro (Jan), fevereiro (Fev) e março(Mar); (b,f) abril (Abr), maio (Mai) e junho (Jun); (c,g) julho (Jul), agosto (Ago) e setembro (Set); e (d,h) outubro (Out), novembro (Nov) e dezembro (Dez). Observe que os valores às 0 e 24 HL (hora local) são iguais e que a resolução temporal dos dados é de 3 horas.

Fonte dos dados: LAHMEPE/ITEP e CPTEC/INPE. 


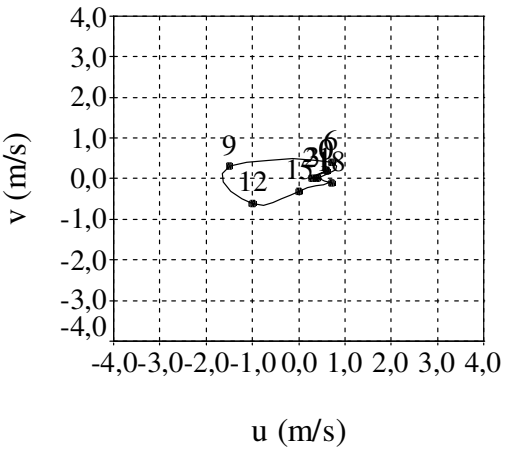

(a)

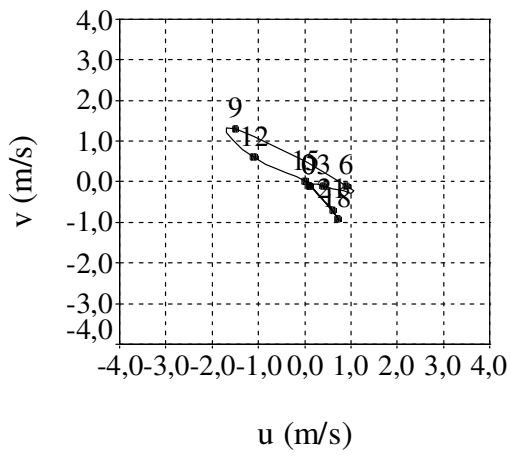

(d)

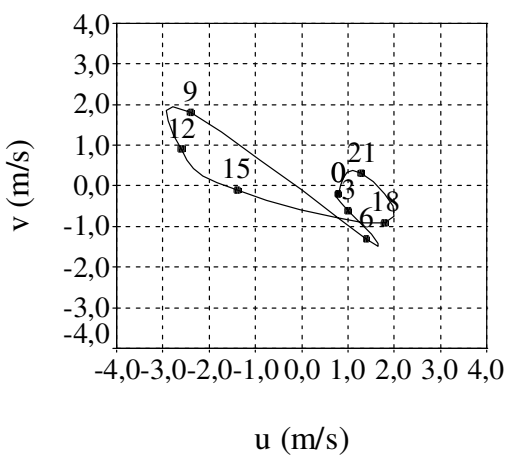

(g)

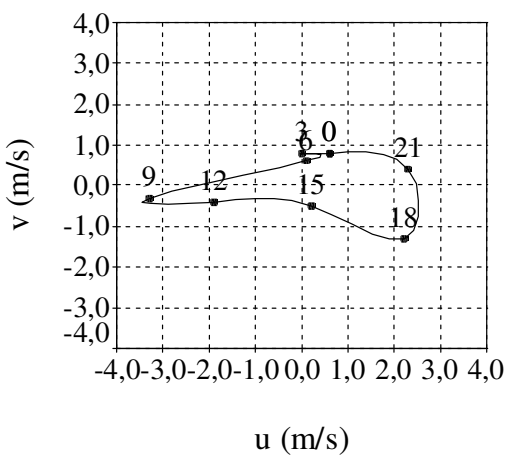

(j)

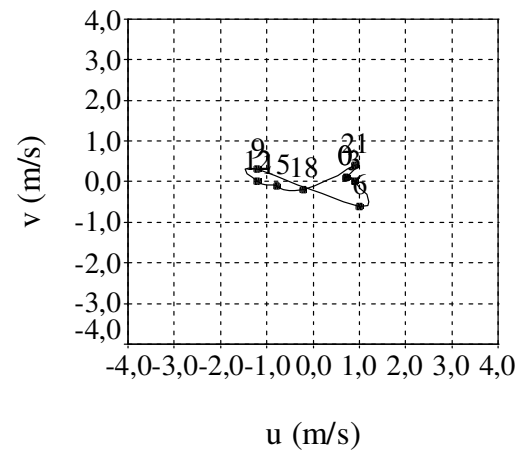

(b)

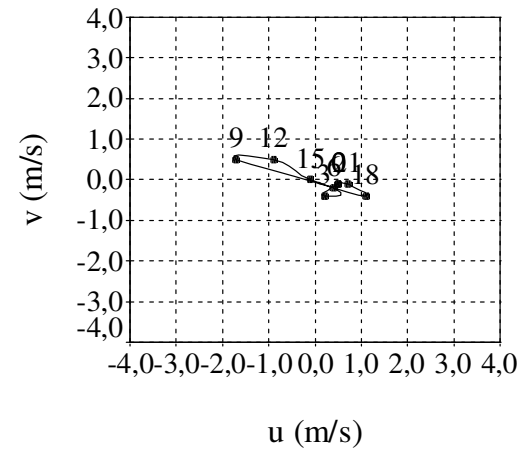

(e)

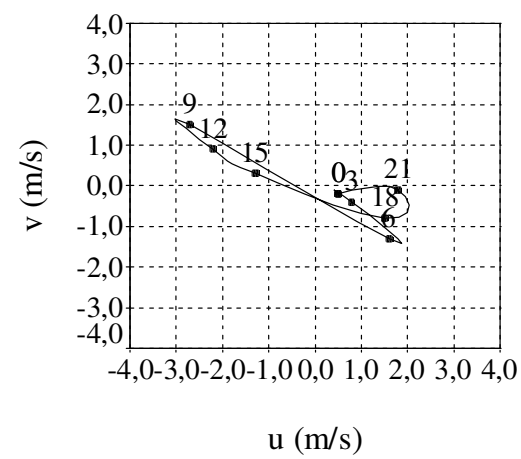

(h)

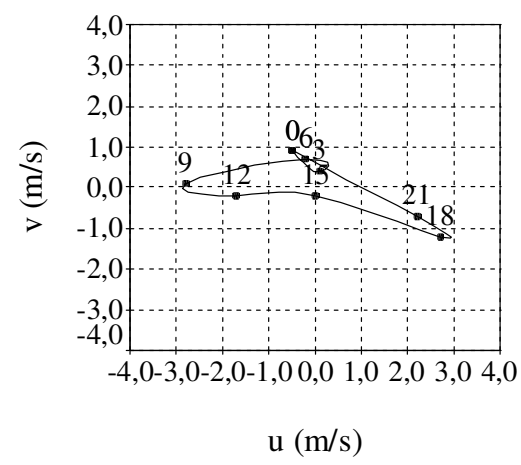

(k)

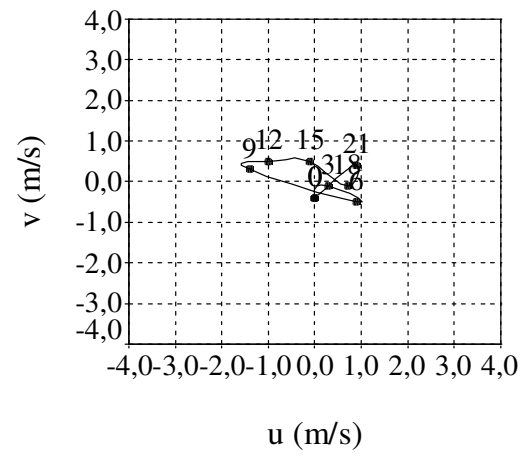

(c)

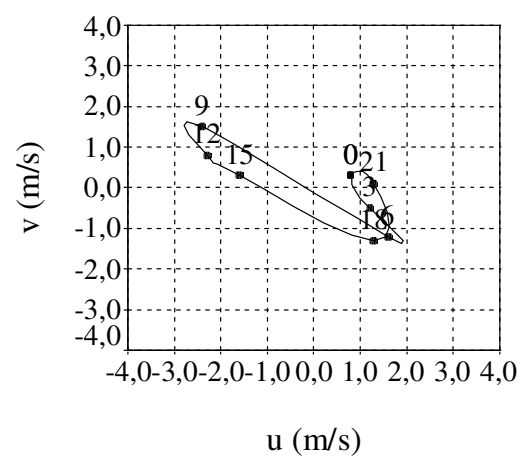

(f)

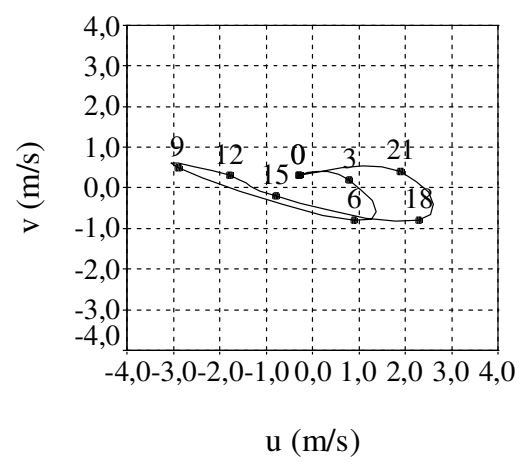

(i)

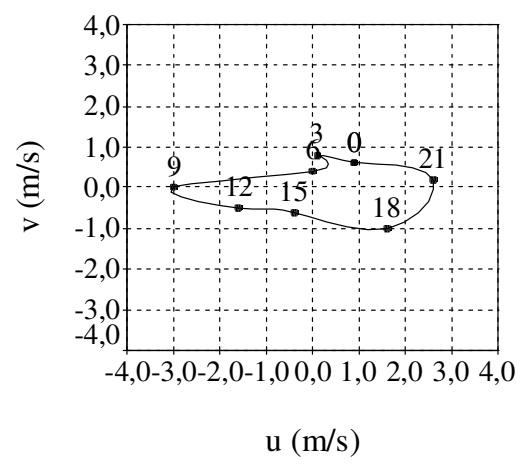

(1)

Figura 4 - Hodógrafo do vento local na Plataforma de Coleta de Dados (PCD) de Petrolina-PE para o mês de: (a) janeiro, (b) fevereiro, (c) março, (d) abril, (e) maio, (f) junho, (g) julho, (h) agosto, (i) setembro, (j) outubro, (k) novembro e (l) dezembro. Os círculos e valores nos gráficos assinalam a hora local.

Fonte dos dados: LAHMEPE/ITEP e INPE/CPTEC. 
estar na relativa complexidade do relevo nas proximidades da PCD, já que há serras em todos os quadrantes, à exceção do sudeste. É evidente em quase todos os hodógrafos que a circulação local é mais intensa em torno das 9 e 18 HL, horários em que são observados, respectivamente, os valores máximos e mínimos principais da velocidade média horária, conforme ilustrado na Figura 3.

\subsection{Análise dos dados da estação convencional}

A variação sazonal do ciclo diário do vento na estação convencional também é investigada através da velocidade (Figuras 5a-5d) e da direção (Figuras 5e-5h) no período 19771981. Os gráficos da velocidade ilustram valores menores (maiores) no primeiro (terceiro) trimestre. $\mathrm{O}$ aumento da velocidade entre março (Figura 5a) e setembro (Figura 5c) está relacionado com a intensificação da ASAS. É possível observar ainda que a variação é maior no segundo trimestre, marcando a transição entre o período chuvoso e o período de estiagem (Figura $5 b$ ). Por outro lado, no primeiro e quarto trimestres um dos meses se destaca pelos maiores valores de velocidade: janeiro (Figura 5a) e outubro (Figura 5d). Nos outros meses desses trimestres as velocidades são muito próximas, principalmente no período diurno. A despeito da resolução temporal e período de dados distintos, essas variações sazonais se assemelham àquelas observadas na Figuras $3 \mathrm{a}-3 \mathrm{~d}$ dos dados da PCD. Em contrapartida, a velocidade média diária na estação convencional é aproximadamente metade daquela na PCD, ao longo de todo o ano, uma característica que está diretamente relacionada com a circulação de grande escala. Os gráficos das Figuras 5e-5h mostram direções do quadrante sudeste em todos os meses. Em particular, a direção fica em torno de 130 graus no período de maio a setembro (época de estiagem); suas curvas praticamente se superpõem (Figuras $5 \mathrm{f}-5 \mathrm{~g})$.

O ciclo diário nesta estação também mostra um padrão complexo nos gráficos da velocidade (Figuras 5a-5d): há um máximo no meio da manhã (8-9 HL) e outro na primeira metade da noite (21-24 HL). Esses máximos têm valores muito próximos na maioria dos meses. Na série da PCD o máximo noturno é visto em alguns meses apenas. Dois mínimos também são evidentes: um no início da manhã ( 5 HL) e outro no final da tarde (17-18 HL). Seus valores são muito próximos no segundo e terceiro trimestres, época de estiagem. No ciclo diário da direção (Figuras $5 \mathrm{e}-5 \mathrm{~h}$ ) há pouca variação no período de maio a setembro (Figuras 5f-5g), quando a direção fica em torno de 130 graus conforme visto anteriormente. As variações são maiores nos meses de janeiro, março, novembro e dezembro (Figuras $5 \mathrm{e}-5 \mathrm{~h}$ ), atingindo cerca de 20 graus entre o período diurno e o período noturno no mês de dezembro.
A variação sazonal das circulações locais na área da estação convencional é ilustrada na Figura 6 . A configuração dos hodógrafos evidencia um eixo de elongação na direção sudestenoroeste. Os ventos locais se concentram nesses quadrantes, particularmente no período de março a agosto (Figuras 6c-6h). Na maioria desses meses, há ventos do quadrante sudeste no período da manhã e início da tarde que são substituídos por ventos do quadrante noroeste no restante do período. Nos meses de janeiro, fevereiro, e de setembro a dezembro, também há ventos dos outros quadrantes. Essa característica é mais evidente no último trimestre do ano (Figuras 6j-61): no período noturno os ventos são dos quadrantes sudoeste e sudeste, este último também no início da manhã. Essas direções são indicativas de ventos catabáticos oriundos das áreas elevadas situadas a sul-sudoeste da cidade. No período diurno os ventos são dos quadrantes nordeste (manhã) e noroeste (tarde). A presença de ventos locais de noroeste no período da tarde em Petrolina parece ser consequência da propagação da brisa lacustre do lago de Sobradinho, de acordo com experimentos numéricos de alta resolução realizados com o Regional Atmospheric Modeling System (RAMS) (Figura 3 de Correia et al., 2006b). Os ventos locais são de noroeste e têm máxima intensidade às 17-18 HL; são de sudeste e têm máxima intensidade às $9 \mathrm{HL}$, com exceção do quarto trimestre (Figuras 6j-61).

\section{CONCLUSÃO}

Neste estudo o ciclo diário do vento à superfície é investigado para a área de Petrolina-PE, localizada no submédio São Francisco, com base nos dados de dois pontos de observação distintos: dados horários da estação convencional de superfície localizada na cidade de Petrolina (período 1977-1981) e dados com resolução temporal de três horas da estação automática localizada na encosta de uma colina a uma distância de 25 a 30 $\mathrm{km}$ da cidade (período 2001-2007).

Os resultados da análise da variação sazonal do ciclo diário mostram características comuns às duas séries de dados, apesar da localização, resolução temporal e períodos de coleta distintos. A velocidade média horária aumenta no decorrer do trimestre abril-maio-junho, final do período chuvoso e início do período de estiagem. O oposto ocorre no trimestre outubro-novembro-dezembro, final do período de estiagem e início do período chuvoso. Os valores são máximos e quase constantes no decorrer do trimestre julho-agosto-setembro, época em que os ventos alísios são mais intensos. É evidente, de maneira geral, em todos os meses, um máximo principal no meio da manhã, em torno das 8-9 HL, e dois mínimos, um no início da manhã (5-6 HL) e outro no final da tarde (17-18 HL). Um máximo secundário é visto em alguns meses, no período noturno. A direção do vento médio varia muito 


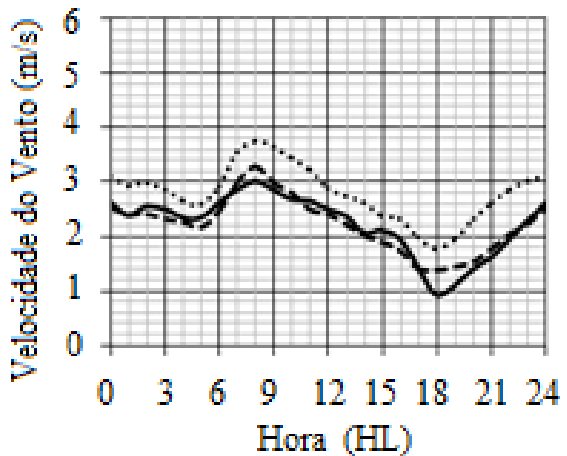

(a)

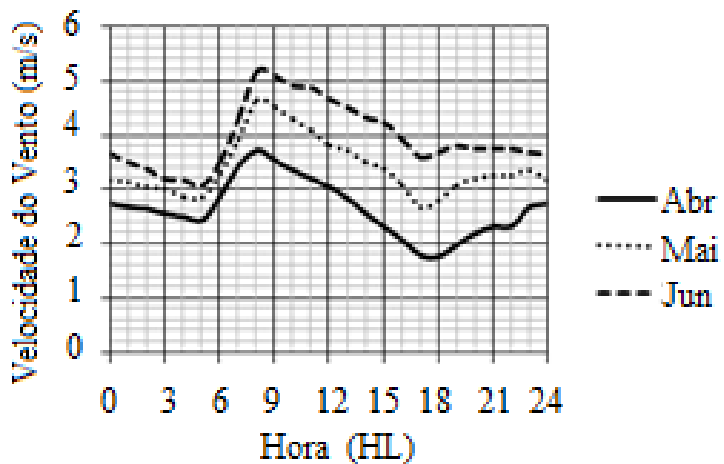

(b)

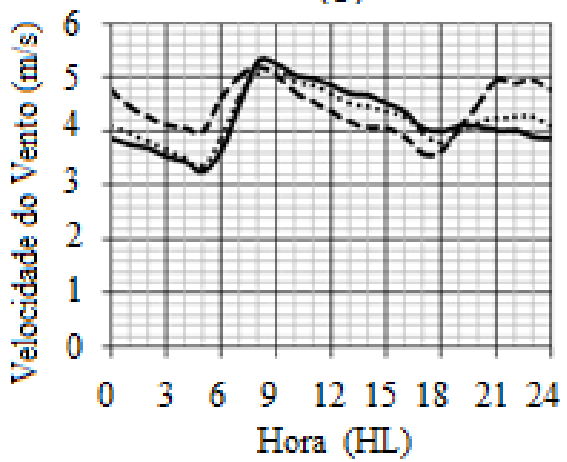

(c)

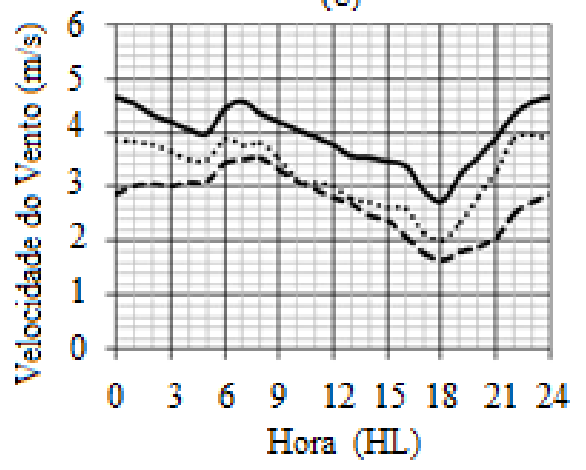

(d)

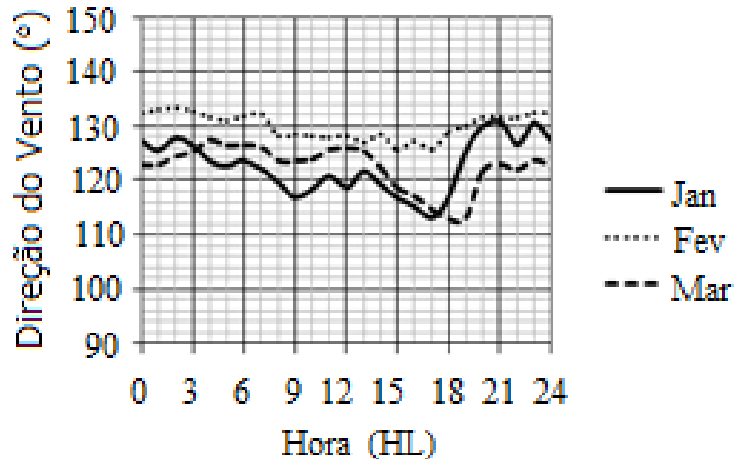

(e)

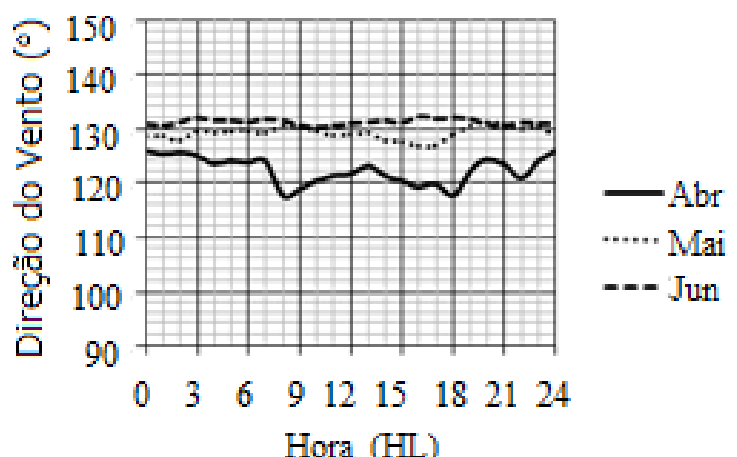

(f)

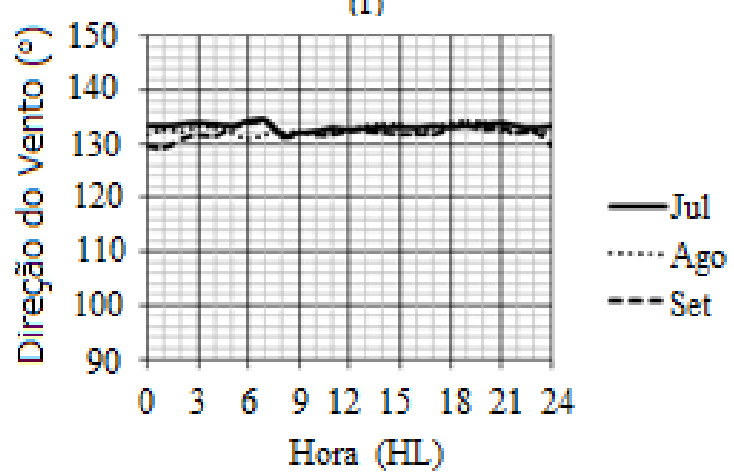

(g)

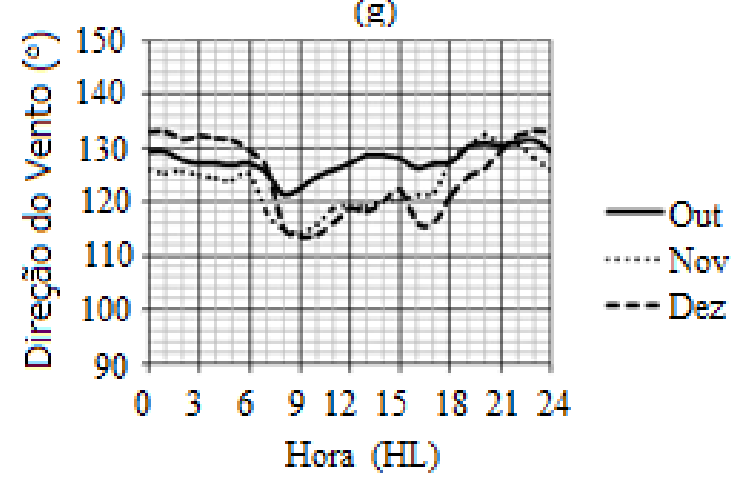

(h)

Figura 5 - Variação sazonal do ciclo diário da velocidade (a, b, c, d) e da direção (e, f, g, h) do vento à superfície na estação convencional de Petrolina-PE para os trimestres: (a,e) janeiro (Jan), fevereiro (Fev) e março (Mar); (b,f) abril (Abr), maio (Mai) e junho (Jun); (c,g) julho (Jul), agosto (Ago) e setembro (Set); e (d,h) outubro (Out), novembro (Nov) e dezembro (Dez). Observe que os valores às 0 e 24 HL (hora local) são iguais e que a resolução temporal dos dados é de 1 hora.

Fonte dos dados: DCA/UFCG e INMET. 


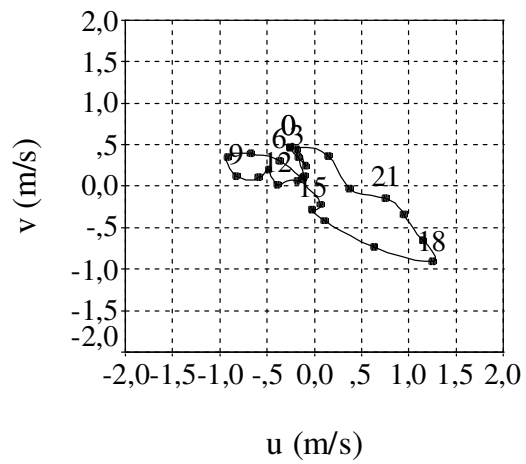

(a)

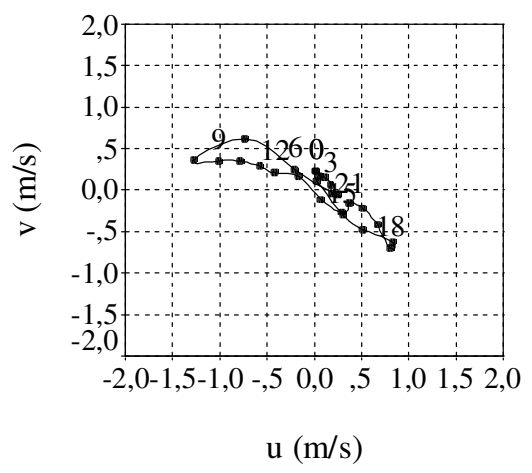

(d)

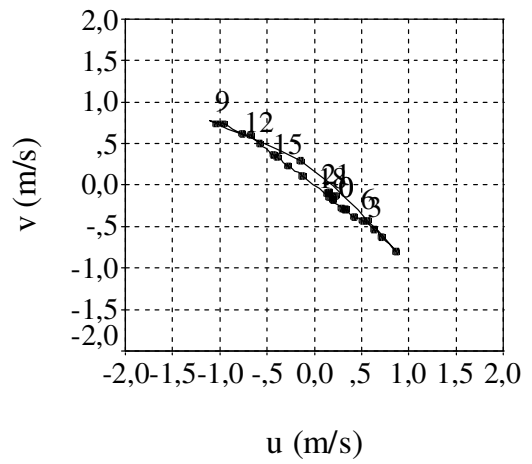

(g)

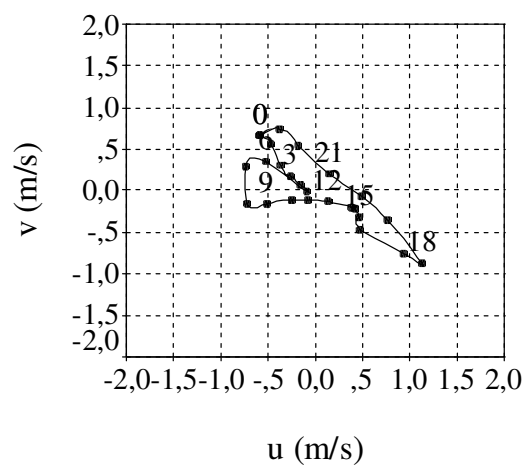

(j)

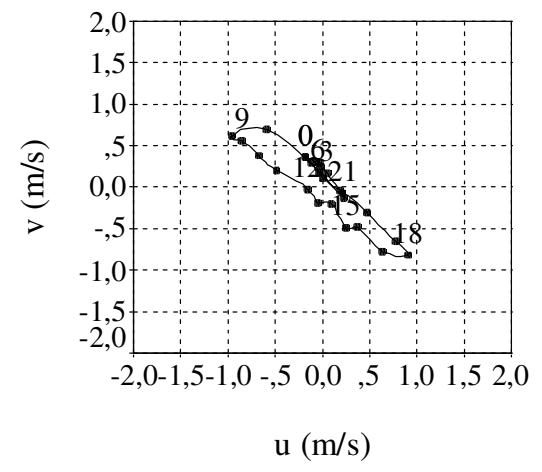

(b)

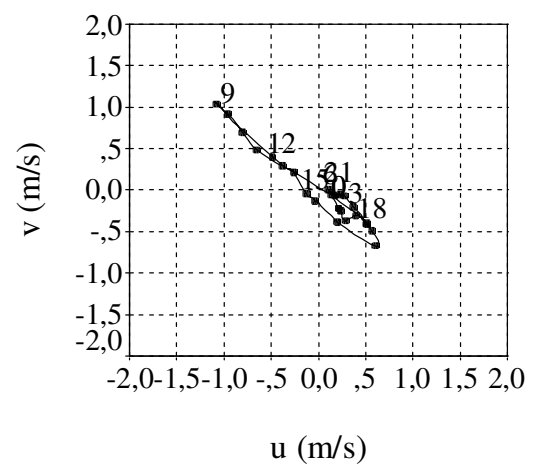

(e)

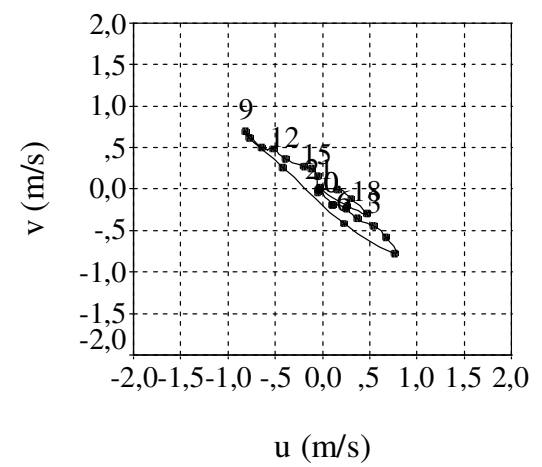

(h)

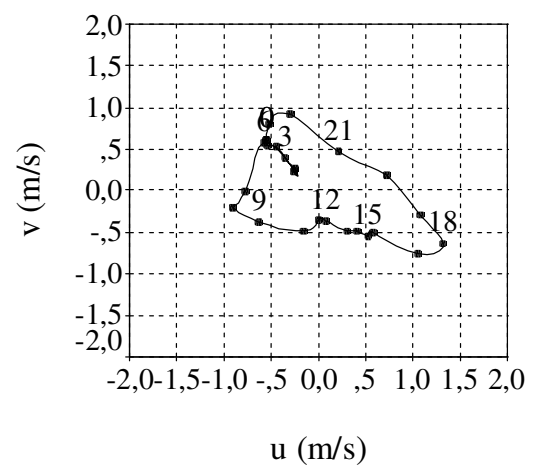

$(\mathrm{k})$

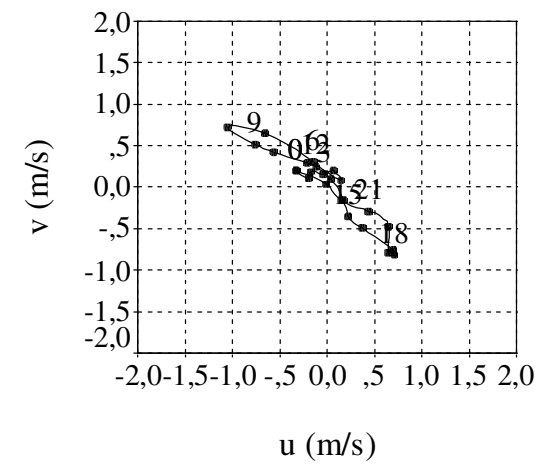

(c)

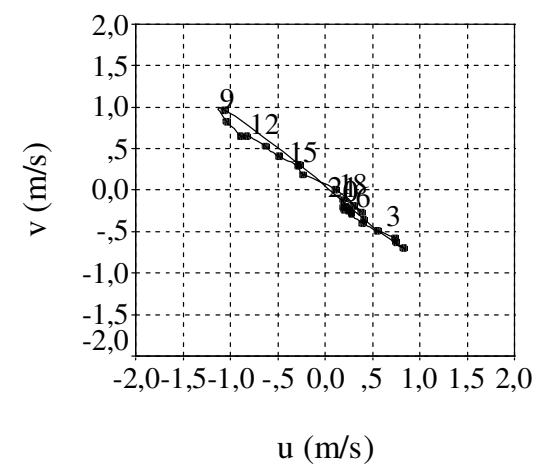

(f)

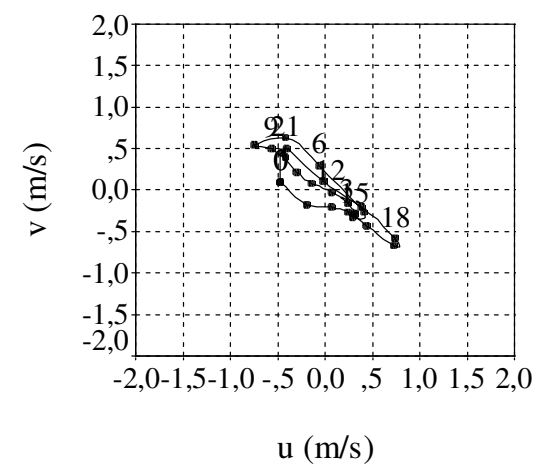

(i)

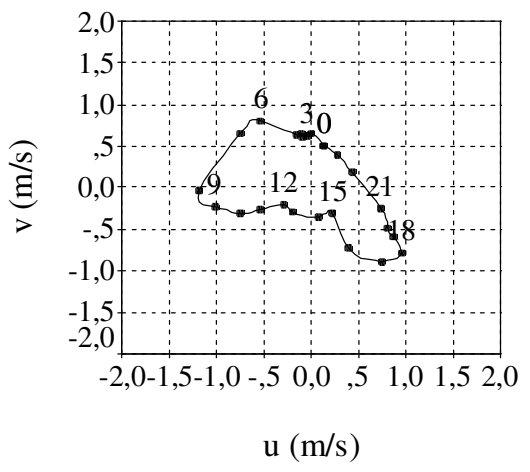

(l)

Figura 6 - Hodógrafo do vento local na estação convencional de superfície de Petrolina-PE para o mês de: (a) janeiro, (b) fevereiro, (c) março, (d) abril, (e) maio, (f) junho, (g) julho, (h) agosto, (i) setembro, (j) outubro, (k) novembro e (l) dezembro. Os círculos e valores nos gráficos assinalam a hora local.

Fonte dos dados: DCA/UFCG e INMET. 
pouco ao longo do ciclo diário durante o período de estiagem (maio a setembro), permanecendo em torno de 130 graus na estação convencional, e no intervalo 120-130 graus na estação automática. A variabilidade é maior no período chuvoso, época de velocidades mais baixas.

Os resultados da análise da variação sazonal do vento local apresentam algumas características comuns e também aspectos distintos devido à situação geográfica particular de cada estação. Os hodógrafos do vento local na estação automática evidenciam um regime preferencial na direção sudeste-noroeste. $\mathrm{O}$ giro do vento é predominantemente anti-horário, exceto em abril e maio. De maneira geral, as mudanças no sentido de rotação são observadas em curtos períodos de tempo, à noite e de madrugada, o que sugere a influência da complexidade do relevo nas proximidades da estação automática, com serras em todos os quadrantes, à exceção do sudeste. A circulação local é mais intensa em torno das 9 e $18 \mathrm{HL}$, com direções preferenciais do quadrante sudeste no período diurno, e do quadrante noroeste no período noturno. As circulações locais são fracas de janeiro a maio, época em que o teor de umidade do solo é maior e, consequentemente, o fluxo de calor sensível é menor.

Os hodógrafos do vento local na estação convencional também evidenciam um giro predominantemente anti-horário, e um regime preferencial na direção sudeste-noroeste, com a particularidade de que há ventos dos outros quadrantes no período de setembro a fevereiro e, principalmente, no último trimestre do ano. À exceção desse trimestre, o vento local é de noroeste no meio e final da tarde e durante a noite, com velocidade máxima às 17-18 HL, e de sudeste no período da manhã e início da tarde, com velocidade máxima às 9 HL. No período de setembro a fevereiro há ventos dos quadrantes sudoeste e sudeste durante a noite, o que sugere a atuação de ventos catabáticos das áreas elevadas localizadas a sul-sudoeste da cidade. Durante o dia, os ventos são dos quadrantes nordeste (manhã) e noroeste (tarde). A presença desses últimos parece ser consequência da propagação da brisa lacustre do lago de Sobradinho.

\section{AGRADECIMENTOS}

Aos revisores pelas sugestões. Ao Laboratório de Meteorologia de Pernambuco/Instituto Tecnológico de Pernambuco (LAMEPE/ITEP) na pessoa de Francis Lacerda, Werônica Meira de Sousa e Romilson Ferreira da Silva e ao CPTEC/INPE pela cessão dos dados da estação automática. À Unidade Acadêmica de Ciências Atmosféricas/Universidade Federal de Campina Grande (DCA/UFCG) e ao Instituto Nacional de Meteorologia (INMET) pela cessão dos dados da estação convencional. À Agência Executiva de Gestão das Águas do Estado da Paraíba (AESA) pela cessão dos dados topográficos do projeto TOPEX. Este trabalho é parte da pesquisa de doutorado desenvolvida pelo primeiro autor com o apoio financeiro do Conselho Nacional de Desenvolvimento Científico e Tecnológico (CNPq) através do Projeto CLIMUD (Processo CNPq 504189/2003-4). O primeiro autor agradece ao Programa de Pós-graduação em Meteorologia da Universidade Federal de Campina Grande (UFCG) e à Coordenação de Aperfeiçoamento de Pessoal de Nível Superior (CAPES) pela concessão de bolsa de estudos.

\section{REFERÊNCIAS BIBLIOGRÁFICAS}

ALPERT, P.; MANDEL, M. Wind variability - An indicator for a mesoclimate in Israel. Journal of Climate and Applied Meteorology, v. 25, p. 1568-1576, 1986.

BARBOSA, T. F.; CORREIA, M. F. Sistemas convectivos intensos no semi-árido brasileiro: $\mathrm{O}$ controle da grande escala. Revista Brasileira de Meteorologia, v. 20, n. 3, p. 395-410, 2005.

BARRETO, A. B. Estudo do ciclo diário do vento à superfície no Nordeste do Brasil. 2001. 56p. Dissertação (Mestrado em Meteorologia) - Universidade Federal da Paraíba, Campina Grande.

COMPANHIA DE DESENVOLVIMENTO DOS VALES DO SÃO FRANCISCO E DO PARNAÍBA. Projeto de Gerenciamento Integrado das Atividades Desenvolvidas em Terra na Bacia do São Francisco ANA/GEF/PNUMA/OEA Subprojeto 4.5C - Plano Decenal de Recursos Hídricos da Bacia Hidrográfica do Rio São Francisco - PBHSF (20042013), 150pp, 2004.

CORREIA, A. A. Padrões de variabilidade do vento à superfície no Nordeste do Brasil. 2000. 66p. Dissertação (Mestrado em Meteorologia) - Universidade Federal da Paraíba, Campina Grande.

CORREIA, M. F. Impacto das Ações Antrópicas no Clima do Submédio do Rio São Francisco: Um Estudo Numérico e Observacional. 2001. 181p. Tese (Doutorado em Meteorologia) - Universidade de São Paulo, São Paulo. CORREIA, M. F.; SILVA DIAS, M. A. F.; SILVA ARAGÃO, M. R. Soil occupation and atmospheric variations over Sobradinho Lake area. Part One: An observational analysis. Meteorology and Atmospheric Physics, v. 94, p. 103-113, 2006a. DOI 10.1007/s00703-005-0173-4

CORREIA, M.F.; SILVA DIAS, M.A.F.; SILVA ARAGÃO, M.R. Soil occupation and atmospheric variations over Sobradinho Lake area. Part Two: A regional modeling study. Meteorology and Atmospheric Physics, v. 94, p. 115-128, 2006b. DOI 10.1007/s00703-005-0174-3

DAMIÃO, M. C. Um estudo das condições atmosféricas em janeiros secos e chuvosos no semi-árido do Nordeste do 
Brasil e sua relação com a chuva em meses posteriores na região. 1999. 158p. Dissertação (Mestrado em Meteorologia) - Universidade Federal da Paraíba, Campina Grande.

DEXTER, R. V. The sea-breeze hodograph at Halifax. Bulletin of the American Meteorological Society, v. 39, n. 5, 1957.

DINIZ, M. C., CORREIA, M. F., SILVA ARAGAO, M. R. Convecção profunda no submédio do Rio São Francisco: Uma avaliação das condições atmosféricas na área do aeroporto de Petrolina - PE. Revista Brasileira de Meteorologia, v. 19, p. 273-286, 2004.

EMBRAPA SEMI-ÁRIDO. Sistemas de Produção, 1ISSN 1807-:0027 Versão Eletrônica 2004. Disponível em http:// www.cpatsa.embrapa.br/index.php?op=sp. Acesso em 15 nov. 2005.

HANDAR MODELS 425A/425AH ULTRASONIC WIND SENSORS GUIDE. Handar Business Unit. Vaisala Corp., 1999.

HAURWITZ, B. Comments on the sea-breeze circulation. Journal of Meteorology, v. 4, p. 8, 1947.

KOUSKY, V. E. Frontal influences on Northeast Brazil. Monthly Weather Review, v. 107, p. 1140-1153, 1979.

KOUSKY, V. E.; GAN, M. A. Upper tropospheric cyclonic vortices in the tropical South Atlantic. Tellus, v. 33, p. 538-551, 1981.

KUSUDA, M.; ALPERT, P. Anticlockwise rotation of the wind hodograph. Part I: Theoretical study. Journal of the Atmospheric Science, v. 40, p. 487-499, 1983.

MAHFOUF, J. F.; RICHARD, E.; MASCART, P. The influence of soil and vegetation on the development of mesoscale circulations. Journal of Climate and Applied Meteorology, v. 26, p. 1483-1553, 1987.

McKENDRY, I. G. Spatial and temporal aspects of the surface wind regime on the Canterburry plains, New Zealand Journal of Climatology, v. 3. p. 1555-1566, 1983.

MELO, E. C. S. Simulação numérica de circulações de brisa no estado da Paraíba. 2000. 74p. Dissertação (Mestrado em Meteorologia) - Universidade Federal da Paraíba, Campina Grande.
MOSCATI, M. C. L.; GAN, M. A. Rainfall variability in the rainy season of semiarid zone of Northeast Brazil (NEB) and its relation to wind regime. International Journal of Climatology, v 27, p. 493-512, 2007. DOI: 10.1002/ joc. 1408.2006.

RAMOS, R. P. L. Precipitation characteristics in the Northeast Brazil dry region. Journal of Geophysical Research, v. 80, n. 12 , p. 1665-1678, 1975.

SANTOS SILVA, F. D.; CORREIA, M. F.; SILVA ARAGÃO, M. R.; SILVA, J. M. Convecção linearmente organizada na área de Petrolina, semi-árido do Nordeste do Brasil: Aspectos em meso e grande escala. Revista Brasileira de Meteorologia, v. 23, n. 3, p. 292-304, 2008.

SILVA ARAGÃO, M. R.; CORREIA, M. F.; ARAÚJO, H. A. Characteristics of C-band meteorological radar echoes at Petrolina, Northeast Brazil. International Journal of Climatology, v. 20, p. 279-298, 2000.

SILVA ARAGÃO, M. R.; CORREIA, M. F; SOBRAL, Z. R. Vento à superfície e chuva em anos contrastantes no submédio São Francisco. II Simpósio Brasileiro de Climatologia Geográfica. Boletim Climatológico, v. 2, n. 3, p. 213-217, 1997.

SILVA ARAGÃO, M. R.; MENDES, M. C. D.; CAVALCANTI, I. F. A.; CORREIA, M. F. Observational study of a rainy January day in the Northeast Brazil semi-arid region: Synoptic and mesoscale characteristics. Quarterly Journal of the Royal Meteorological Society. v. 133, p. 1127-1141, 2007. DOI 10.1002/qj.81

SIlVA, B. B.; AlveS, J. J. A.; CAVAlCANTI, E. P.; VENTURA, E. D. Variabilidade espacial e temporal do potencial eólico da direção predominante do vento no Nordeste do Brasil. Revista Brasileira de Meteorologia, v. 19, n. 2, p. 189-202, 2004.

SOUZA, P. P. Estudo da atuação de um sistema de latitudes médias no semi-árido do Nordeste do Brasil. 2003. 102p. Dissertação (Mestrado em Meteorologia) - Universidade Federal de Campina Grande, Campina Grande. 